\title{
Physical and psychological evaluation of 'non-organic' abdominal pain
}

\author{
OSCAR W. HILL AND LAURENCE BLENDIS \\ From the Department of Medicine and the Academic Department of Psychiatry, \\ The Middlesex Hospital, London
}

EDITORIAL COMMENT A study of the psychiatric background of patients with abdominal pain without demonstrable physical disease. The patients came from significantly larger sibships than a control population and scored high for 'neuroticism'. The patients' symptoms often began in a setting of bereavement or some other upheaval in their lives. A number of patients were considerably depressed when seen and treatment for depression was followed by disappearance of pain. This offers an important therapeutic approach in many patients.

A considerable proportion of the patients at any medical out-patient clinic have no organic lesion to account for their symptoms (see review by McClay, 1965). One of the commonest complaints in this category is pain and when this occurs in the abdomen it may well give rise to difficulty in diagnosis and treatment.

The absence of organic disease in such a patient implies an increased likelihood that psychological factors may play an important part in the aetiology of the patient's symptoms. In order to explore this possibility and also to attempt to try to define the clinical picture of abdominal pain occurring in the absence of structural change, a group of these patients was carefully investigated both from the clinical and psychological points of view.

\section{STUDY AND METHOD}

The group that was studied comprised all the patients seen by one of the authors (L.M.B.) who complained of abdominal pain for which no organic cause could be established. They were all seen in the course of one year's routine out-patient work in the hospital.

When first seen by the physician all patients were questioned and examined with a view to establishing a diagnosis of organic disease. Sigmoidoscopy and lactose tolerance tests were performed on any patient with a history of change in bowel habit, and radiological investigations were performed as indicated. Patients with epigastric pain and a normal barium meal were then offered gastro-photography (Hadley, 1965).

We have excluded from our 'non-organic' group any patient with hiatus hernia, gallstones, or colonic diverticula, however remotely connected with the pain these lesions might appear.

When an organic cause had been as far as possible ruled out, all the patients were invited to see a psychiatrist (O.W.H.). It is important to emphasize that every single patient seen by L.M.B. falling into this category has been included in this study and not just those in whom there was a suspicion of psychiatric disturbance. In all, 31 patients were considered to have 'non-organic' abdominal pain and of these only three declined to see the psychiatrist and one spoke such poor English that it was impossible to make a satisfactory psychiatric assessment. There is limited information about these four patients included in the results.

Each patient was seen by the psychiatrist initially for one to one and a half hours in an unstructured clinical interview, after which the patient completed a Eysenck personality inventory. On the basis of this interview, it was decided whether the patient required further psychiatric treatment in the form of psychotherapy, drugs, or both, and such treatment was carried out as indicated. Where such clear indications were lacking and the pain persisted the patient was included in a double-blind trial using Perphenazine, Amytal, and a placebo.

For the purposes of certain comparisons two groups of patients were used. One group consisted of patients with peptic ulceration seen by L.M.B. in the out-patient department during the same period of time. The second group were in-patients suffering from a variety of definite organic illnesses and interviewed by O.W.H. to ascertain the occurrence of abdominal pain in their parents.

\section{RESULTS}

In all 31 patients were considered by the physician to be suffering from 'non-organic' abdominal pain, 27 of whom were satisfactorily assessed by the psychiatrist.

In the description of their physical symptoms, the 
patients could be assigned to one of three syndromes. The largest group (19) comprised those patients who complained of epigastric pain without any disturbance of bowel action. There were a further six patients with right hypochondriacal pain and a normal bowel action and six with pain at various sites accompanied by disordered bowel action. This latter group were considered to be suffering from the irritable colon syndrome. To some extent the above division is rather arbitrary; for example, epigastric pain may be caused by an irritable colon without any apparent disturbance of bowel function. The division is useful for a consideration of differential diagnosis, especially in the group with epigastric pain where the physician is concerned that he may be missing a peptic ulcer.

In order to throw some light on the clinical differentiation of our patients with non-organic epigastric pain from ulcer patients, a comparison of symptoms has been made with a group of ulcer patients seen by the same physician and matched for age, sex, and nationality.

There were 19 patients in each group. Table I compares the patients for the classical features of ulcer pain. It will be seen that periodicity and relief by meals is significantly commoner in the ulcer patients. There is a similar trend in nocturnal pain and a more frequent report by the 'non-organic' group of exacerbation by meals but neither of these achieve formal levels of statistical significance. The patients with non-organic pain often found difficulty in describing their pains and would use analogies that were rarely employed by the ulcer patients, such as, knife-like and sharp, a burning sensation, band-like, a tightness across the upper abdomen, soreness, a great pressure and a weight across the abdomen. Only one patient described it as a hunger pain which also came on at night but the pain was never relieved by food and the picture was clouded by a number of bizarre symptoms.

Table II presents the symptoms of which the non-organic patients commonly complained and comparison is made with the frequency of these

\section{TABLE I}

THE INCIDENCE OF CLASSICAL PEPTIC ULCER SYMPTOMS IN PATIENTS WITH PEPTIC ULCERATION COMPARED IN THOSE WITH THE 'NON-ORGANIC' EPIGASTRIC PAIN SYNDROME

\begin{tabular}{lrcc} 
Symptom & $\begin{array}{c}\text { Patients with } \\
\text { Peptic Ulcer }\end{array}$ & $\begin{array}{l}\text { Patients with } \\
\text { Epigastric } \\
\text { Pain }\end{array}$ & P \\
\hline Periodic pain & 17 & 5 & P $<0.001^{1}$ \\
Pain exacerbated by meals & 5 & 9 & N.S. \\
Pain relieved by meals & 12 & 0 & P $<0.001^{1}$ \\
Nocturnal pain & 5 & 1 & N.S. \\
${ }^{1}$ Calculated by fourfold table test. & N.S. $=$ Not significant.
\end{tabular}

symptoms among the ulcer patients. Nausea was not only a more frequent complaint in the nonorganic group but was a more prominent symptom, often being continuous, without relief, although less likely to be associated with vomiting. Distension and belching were significantly commoner in the nonorganic group.

\section{TABLE II}

INCIDENCE OF THE PREDOMINANT SYMPTOMS IN PATIENTS WITH 'NON-ORGANIC' EPIGASTRIC PAIN COMPARED WITH PEPTIC ULCER PATIENTS

\begin{tabular}{lccl} 
Symptom & $\begin{array}{c}\text { Patients with } \\
\text { Peptic Ulcer }\end{array}$ & $\begin{array}{c}\text { Patients with } \\
\text { Epigastric Pain }\end{array}$ & P \\
\hline Nausea & 6 & 16 & P $<0.005$ \\
Vomiting & 6 & 4 & N.S. \\
Distension & 4 & 13 & P $<0.025$ \\
Belching & 5 & 13 & P $<0.025$
\end{tabular}

The length of history from the first attack of pain is set out in Table III and it will be seen that the non-organic group had significantly longer histories. Changes of weight are seen in Table IV, with a significantly greater loss among the ulcer patients. The findings on physical examination (Table V) showed little difference. Of those patients who had been examined by gastro-photography it was only amongst the non-organic group that there were any reports that their accustomed pain was induced by the procedure. Numbers were too small to achieve statistical significance (Table VI).

\section{TABLE III}

COMPARISON OF LENGTH OF HISTORY BETWEEN PEPTIC ULCER PATIENTS AND THOSE SUFFERING FROM 'NON-ORGANIC' EPIGASTRIC PAIN

\begin{tabular}{ccc}
$\begin{array}{l}\text { Length of History } \\
(y r .)\end{array}$ & $\begin{array}{l}\text { Patients with } \\
\text { Peptic Ulcer }\end{array}$ & $\begin{array}{l}\text { Patients with } \\
\text { Epigastric Pain }\end{array}$ \\
\hline $0-1$ & 6 & 2 \\
$1-2$ & 4 & 0 \\
$2-5$ & 5 & 7 \\
$5-10$ & 3 & 4 \\
$>10$ & 1 & 6
\end{tabular}

Comparing total length of histories in two groups, $x^{2}=8 \cdot 12 \mathrm{~d}$. f., $\mathbf{P}=<0.02$ (first two and last two cells combined).

\section{TABLE IV}

COMPARISON OF WEIGHT CHANGES BETWEEN PATIENTS WITH PEPTIC ULCER AND 'NON-ORGANIC' EPIGASTRIC PAIN

$\begin{array}{lll}\text { Change in Weight } & \text { Patients with } & \begin{array}{l}\text { Patients with } \\ \text { (st.) }\end{array} \\ & \text { Peptic Ulcer } & \text { 'Non-organic' } \\ \text { Epigastric Pain }\end{array}$

\begin{tabular}{llc}
\hline Lost $>1$ & 4 & 0 \\
$\frac{1}{2}-1$ & 3 & 0 \\
$<\frac{1}{2}$ & 3 & 2 \\
No change & 7 & 12 \\
Gain $<\frac{1}{2}$ & 2 & 3 \\
$\frac{1}{2}-1$ & 0 & 0 \\
$>1$ & 0 & 2 \\
Combining all patients who lost weight in two groups, $x^{2}=7 \cdot 8$ \\
1 d. f., $P=<0.01$.
\end{tabular}


TABLE V

INCIDENCE OF EPIGASTRIC TENDERNESS IN PATIENTS WITH NON-ORGANIC EPIGASTRIC PAINS AND THOSE WITH PEPTIC ULCER

\begin{tabular}{lcc} 
Abdominal Findings & $\begin{array}{c}\text { Patients with } \\
\text { Peptic Ulcer }\end{array}$ & $\begin{array}{c}\text { Patients with } \\
\text { Epigastric Pain }\end{array}$ \\
\hline N.A.D. & 9 & 10 \\
Epigastric tenderness & 10 & 9
\end{tabular}

TABLE VI

COMPARISON OF EFFECT OF GASTRIC DISTENSION IN PATIENTS WITH PEPTIC ULCER AND NON-ORGANIC EPIGASTRIC PAIN

\begin{tabular}{lll} 
Patient Group & $\begin{array}{l}\text { Number of Patients } \\
\text { Undergoing Gastro- } \\
\text { Camera Examination }\end{array}$ & $\begin{array}{l}\text { Pain Simulating } \\
\text { Patients' Symptoms }\end{array}$ \\
\hline
\end{tabular}

\begin{tabular}{lrr}
\hline Peptic ulcer & 11 & 0 \\
Epigastric pain & 9 & 4
\end{tabular}

RIGHT HYPOCHONDRIACAL PAIN This group was too small (6) for us to be able to make any valid comparisons. Cholecystograms and radiographs of the thoracic spine were taken in all these patients in addition to a barium meal. All investigations were normal. In the plain radiograph of the abdomen only one patient was shown to have a large collection of air in the hepatic flexure of the colon.

Their length of history varied from one and a half to 20 years and five out of six complained of nausea and a feeling of distension.

IRRITABLE COLON SYNDROME Sigmoidoscopy and barium enema were all normal in the six patients of this group. Their symptoms conformed to the general pattern as described in the much larger group of cases by Chaudhary and Truelove (1962). One organic condition that has recently been distinguished from the irritable colon syndrome is hypolactasia, in which there is deficiency of intestinal lactase (Haemmerli, Kristler, Ammann, Marthaler, Semenza, Auricchio, and Prader, 1965). Although there is usually a history of milk intolerance these patients may present with non-specific attacks of colicky abdominal pain and diarrhoea (McMichael, Webb, and Dawson, 1965). The lactose tolerance test is a satisfactory screening test (Welsh, Rohrer, and Walker, 1966). Since none of our patients had abnormal tolerance curves further investigations, such as estimation of intestinal disaccharidase activities (Dahlqvist, 1964), were not performed.

PSYCHOLOGICAL AND SOCIAL FINDINGS Due to the small size of the subgroups it was decided to examine psycho-social factors in the group as a whole.
Family history of abdominal pain A striking finding in this group of patients was that in 16 of 31 , one or both parents had suffered from abdominal pain. There were five fathers and 12 mothers (both parents of one patient were included). In retrospect it was not easy to be sure of the cause of the parental pain but in eight of the cases it appeared to be of organic origin and in six it had no known organic cause. Two parents had a long history of abdominal pain for which no cause could be established, eventually dying of abdominal disease almost certainly unrelated to their original symptoms. Seven of the parents had died of conditions which were terminally associated with considerable and memorable pain (including both parents of one patient).

In order to assess the significance of this finding, a comparison was made with the data available from a group of in-patients, who were questioned with the specific object of ascertaining a parental history of abdominal pain of any sort. Of the 27 patients who comprised this group, five reported a parent suffering from abdominal pain one of whom possibly had a peptic ulcer, another had died of carcinoma of the stomach, and the remaining three appear to have had no organic cause for their pain.

Comparing the frequency of individuals with a parental history of abdominal pain (16/31 $v 5 / 27)$, there is a significantly greater incidence in our non-organic group ( $P=<0.02$, fourfold table test). The discrepancy between individuals with a parent dying with an associated painful abdominal condition (6/31 $v$ 1/37) does not quite reach a conventional level of significance $(P=0.08$, Fisher's exact probability).

Personality traits The difficulties of making valid observations on the personalities of patients from clinical interview are very considerable, especially when the main source of information is the patient's own account. In this series of patients, clinical impression was supplemented by the administration of a personality inventory devised by Eysenck (Eysenck and Eysenck, 1964). The inventory was not given to the earlier patients in the series so that it was completed by only 20 of the patients.

Within the limits of our approach, the personalities of these patients tended to the conscientious with high standards of personal behaviour. Many of them belonged to callings in which such qualities are commonly found and are valued, e.g., accountant, solicitor, tax inspector, architect, skilled craftsman, etc. Some of them had pronounced compulsive and phobic traits. As might be expected, associated with these traits was the tendency not to give vent to aggressive feelings and to look inwards rather than outwards for the fault when personal relationships 
went awry. The personality inventory measures two factors, $\mathrm{E}$ and $\mathrm{N}$, which approximate to "extraversion' and 'neuroticism'. The results on the 20 patients of this series who were tested were, $\mathrm{E}=24 \cdot 6 \pm 6 \cdot 9, \mathrm{~N}=27 \pm 9 \cdot 8$, 'lie' scale 5.8 $\pm 3 \cdot 4$. Applying a $t$ test for comparison with established norms, $t$ for $E=1.0$, for $N=3.4$, for 'lie' $=0.9$, hence only the result for $\mathrm{N}$ surpasses conventional levels of significance.

Within the limits of the procedure, these patients appear to be more 'neurotic' than a normal population.

Family size There is some evidence that a complaint to a doctor of pain is more likely to come from the member of a large sibship (Gonda, 1962; Merskey, 1965).

In enumerating the sibships in our patients and controls, all children who had survived the neonatal period were included. In two cases where there were half siblings, these were included as they had been brought up together in the family group.

The control group was constructed from the peptic ulcer group and the in-patient organic group used for other comparisons earlier in this paper. Family size in the general population is closely related to social class and epoch of birth. To control for these factors, the social class of each patient was determined (Registrar General's classification). As the crude control group was bigger and had a higher average age than the non-organic group, the following procedure was used: having placed the members of both groups in their appropriate social class, then for each social class the oldest members in the control group were discarded seriatim without any selection other than age until the number equalled that in the experimental group. This having been carried out for each social class, two groups were left with an exactly similar social class distribution, although the mean age of the control group still remained somewhat greater (45.5 v 39 years). This difference in age is acceptable because it would tend to reduce the chances of verifying the hypothesis.

The data for comparison were as follows:

No. in total

sibship

Patients with ab-

dominal pain

Controls

$\begin{array}{llllllllll}1 & 2 & 3 & 4 & 5 & 6 & 7 & 8 & 9 & 10\end{array}$

$\begin{array}{lllllllll}4 & 8 & 2 & 2 & 7 & 4 & 2 & 1 & 0\end{array}$

(he intermediate sibships to make three cells $(1+2,3+4+5+6+7,8+), \chi^{2}=6 \cdot 4$, df $=2, P=<0.05$.

In interpreting these results it should be borne in mind that Gonda found a general tendency for patients complaining of pain to be members of large sibships even though the pain might be organic in origin. The majority of the control group had pain as a symptom which, just as with the discrepancy in age, works against our hypothesis. Despite these two adverse effects, the hypothesis is substantiated so that the 'true' significance of the difference is probably greater than stated. The mean size of the sibships in our pain group is 5.4 and in our control group is 4 . The crude figure for Great Britain is 2.53 (quoted by Gonda, 1962).

Onset of symptoms In nine of the patients the onset of symptoms was closely associated with the death of a parent; in five of these patients there was a similar episode of pain at the death of the other parent. Of these nine patients, seven gave a history of abdominal pain in a parent (in five it was in the parent whose death precipitated the pain). In one further patient, the parent had died of a carcinoma of the cervix with secondaries in the abdomen although the patient did not recall that the mother had suffered much abdominal pain. The patient had nursed her throughout the terminal illness and came complaining of pain in the lower abdomen.

In 12 patients the pain seemed to be significantly related to difficulties with a spouse or a girl friend. Briefly the situations involved desertion, divorce proceedings, extreme antagonism from a mother to an engagement, two prolonged engagements with pressure for marriage from the fiancée, and six cases of persistently hostile or frustrating behaviour in the spouse. It is of some interest that this last group contained four out of the five patients who suffered from vomiting in addition to abdominal pain (see Hill, 1967).

In seven patients there appeared to be a relationship between the onset of symptoms and particular difficulties at work or with examinations.

Depression Somatic symptoms are often part of a depressive illness and in some cases may dominate the clinical picture. Six of our patients appeared to be suffering from a state of depression when seen, to such an extent that antidepressant drugs were administered. Amitryptilline or Imipramine was used, depending on the accessory symptoms. All patients were seen regularly by the psychiatrist during the course of their treatment. Five of these patients were markedly relieved of their symptoms and also had a general increase of the sense of wellbeing. The sixth, who did not respond, had been chronically depressed for about 25 years, throughout which time she had suffered from abdominal pain. Three of these patients had a family history of mental disturbance as did also a further five of the patients who did not appear to be unduly depressed when seen. It was difficult to ascertain with precision what the illnesses of family members had been but most appeared to have been depressive episodes. 
All but one of these patients presented with the 'cpigastric' syndrome and had suffered pain for one, two, two, three, and 11 years.

\section{TREATMENT AND RESULTS}

Eight patients in this series were submitted to a controlled trial of drugs (see above); most of the remainder were treated clinically as indicated after assessment of their condition. The depressed patients have already been considered.

Four patients improved immediately after their interview with the psychiatrist, although the position was complicated in two cases by the general practitioner having prescribed Probanthine. Nonetheless the possible value of one cathartic experience may be considerable. Certainly in one of these patients who harboured a huge resentment against his wife (apparently justified) and who was unable to talk about it to anyone in his own circle found great relief after unburdening himself at the interview.

Two patients had a series of psychotherapeutic interviews, during which time they have appeared to improve.

The remainder have had a variety of drug treatments and it is not possible to make any useful generalization about them.

One of the authors who is in no way involved in the drug trial has inspected the preliminary results. There are no statistically significant conclusions to be drawn at this stage, but the trend is for most patients to be helped by the two pharmacologically active drugs and to maintain improvement thereafter. The patients started on placebos did not respond until they were given one of the other drugs.

\section{DISCUSSION}

Before proceeding to a discussion of our findings, we must first consider the possibility that the symptoms of these patients may have been due to an organic lesion that eluded detection. There are a number of lines of evidence that support us in our belief that this was not the case.

The majority of patients with peptic ulcer present with a history suggestive of the disorder. Kurokawa (1959) found an incidence of epigastric periodic pain in $90 \%$ of his ulcer patients and in $58 \%$ the pain was relieved by food. Not infrequently a patient presents with classical ulcer symptoms but the barium meal is normal. In a series of such patients followed for five to seven years, about $10 \%$ went on to develop ulcers (Barfred, 1959; Brummer and Hakkinen, 1959) and some may have been suffering from 'chronic duodenitis' (Beck, Kahn, Lacerte,
Solymar, Callegarini, Geokas, and Phelps, 1965). Furthermore, patients with classical ulcer symptoms and normal barium meals are at greater risk for developing an ulcer than those with less specific symptoms (Whitby, 1958). Thus it is very unlikely that even two of our patients will develop a peptic ulcer and even if they did, its relation to their current symptoms would still be open to question.

A further pointer stems from the observation that the likelihood of demonstrating an ulcer in a patient complaining of ulcer-like symptoms increases with the length of the history (Barfred, 1959; Ostrow and Resnick, 1959) in contrast to a group of patients whose symptoms were not typical of ulcer (Whitby 1958). As was noted in Table III, our patients with epigastric pain had a significantly longer history than the ulcer patients, 15 out of 17 having had pain for longer than two years. Investigation of our patients with gastro-photography has contributed to reducing the likelihood of missing a gastric lesion. In a series of 117 patients with epigastric pain and a normal barium meal, 13 gastric ulcers were demonstrated by gastrophotography (Blendis, Cameron, and Hadley, 1967).

From our observations there emerged a fairly characteristic picture of the physical complaints of the non-organic patient. They complained of more or less constant pain, unrelieved and sometimes made worse by food. The pain was accompanied by a feeling of distension associated with belching. Nausea was a frequent feature but when present it was not often associated with vomiting. They had rarely lost any weight. The features that best distinguished the ulcer patients from the 'non-organic' group were the symptoms of periodic pain relieved by food associated with loss of weight. Physical examination is not helpful in making the distinction, as has also been observed by Truelove and Reynell (1963).

The possible mechanisms whereby these patients experience pain may reside in an awareness of pain in the higher centres, unaccompanied by any phenomena in the gut. It may otherwise result from an awareness of disordered activity in the gut, the activity having been induced by the subject's psychological state. These two possibilities probably operate simultaneously and potentiate each other. There is no need to elaborate on the responsiveness of the motor and secretory activity of the gut to different states of mind. The information available has been usefully summarized by Wolfe (1965). A less direct mechanism is illustrated by the excessive aerophagia practised by some individuals especially when they are nervous.

Comparing these patients who were anxious with 
those who were calm before intravenous pyelography Maddock (1952) was able to aspirate three times the amount of air from the stomach in the anxious compared with the calm patients. Roth and Bockus (1957) have described the symptoms associated with aerophagia and these symptoms were common in our patients. Nonetheless our patients did not admit to swallowing air and radiography did not disclose excessive amounts of air in the stomach. However, it is suggestive that the pain of four of our patients was reproduced by the introduction of air into the stomach at gastro-photography (Table VI).

PSYCHOSOCIAL FACTORS In trying to understand the significance of the psychogenic factors in our patients we should ideally be able to conclude why, in the face of adverse circumstances, these patients developed abdominal pain rather than some other sort of reaction or indeed why they did not show the stoicism of which many individuals might be capable in similar circumstances. A complete answer to these very pertinent questions is not possible but the evidence collected in this paper suggests some of the determining factors.

The common occurrence of a history of abdominal pain in the parents of our patients may produce an influence in two ways. The patient may either have inherited a sensitive gastrointestinal tract with a low pain threshold to common stimuli or suffers pain due to his identification with a parent, something that is seen particularly when a bereaved person complains of the symptoms of the departed during the period of mourning (Krupp, 1965). The relevance of this mechanism to our patients is probably considerable, especially as in many of them the symptoms began with the death of a parent, the deaths being associated with pain in the abdomen. Another well-recognized setting in which identification gives rise to symptoms is in the Couvade syndrome (Trethowan and Conlon, 1965) where a husband may develop various pains in association with his wife's pregnancy. (In our series two of the spouses also suffered from abdominal pain.) Support for our finding comes from Apley (1959) in his investigation of non-organic abdominal pain occurring in children. He commonly found a family history of abdominal pain, especially in the mother. It is of considerable interest that a group of these children whom he followed for some years continued to be subject to their abdominal pain even into adult life. Merskey (1965), in his investigation of a group of psychiatric patients who complained of persistent pains, of any sort, found a family history of painful suffering significantly more often than in his control group. Kreitman, Sainsbury, Pearce, and Costain (1965) found that among their hypochondriacal patients the symptoms tended to resemble those suffered by their mothers.

Merskey in the same series confirmed the observation of Gonda (1962) that patients complaining of pain tend to come from larger sibships. Our own figures are in agreement, and go further than the previous observations of Merskey in ruling out social class differences as the possible cause of both the report of pain and the larger sibships. Without further investigation of the features associated with being a member of a larger sibship, we can only speculate on the possible mechanisms involved. A ready explanation could be that a complaint of pain would be one of the few ways in which attention and a demonstration of affection could be gained from harrassed parents. Thus it seems. possible that a habitual response arises in which a feeling of distress is equated in the patient's mind with a sensation of pain. Engel (1959) in his study of the 'pain-prone' patient lays down a number of possible mechanisms derived from his study of such patients, especially sufferers from 'atypical facial pain' which was the subject of an earlier work (Engel, 1951). He has observed that these patients often have excessively punitive parents or parents who would display attention to the child only when he was suffering in some fashion. They would grow up with 'masochistic' elements in their personality structure, regarding suffering as their natural lot in life and to some extent welcoming it for the expectation of comforting that it brings in its train.

In our patients, we have already commented on the very definite impression of an excessively punitive environment in childhood but in the absence of more data from a suitable control group it is not possible to assess this factor critically.

In trying to establish whether these patients have any particular form of personality structure we run up against the difficulties of finding meaningful dimensions for the definition of personality and of measuring these dimensions with the minimum of distortion from our preconceived ideas. The clinical interview gives the more sensitive and global view but is seriously subject to the prejudices of the examiner. The self-administered personality inventory is objective but suffers from the superficiality, deceit, etc., that the patient can more readily practise. In one of the earliest works devoted to a 'non-organic' painful abdominal condition, 'mucous colitis' (= irritable colon), White, Cobb, and Jones (1939) observed that these patients usually possessed high personal standards together with a passive dependent type of personality. More recently Avery Jones has made similar observations in functional gastrointestinal disorders generally (Jones and Gummer, 1960). Our conclusions are 
similar but there is no reason to believe that such a personality is specific to the suffering of nonorganic abdominal conditions, but is commonly found in the whole range of psychosomatic and psychiatric disturbance. One of the central ideas in psychosomatic medicine is that somatic symptoms are often induced by the physiological consequences of the suppression of powerful emotions such as rage and fear. It is exactly the personality type as described above that would be most liable to have such feelings provoked without giving them direct expression. As such, they would be more likely to have physical symptoms of all sorts, abdominal pain included.

We must now consider the extent to which the symptoms complained of may have been part of a depressive illness. It is well known that somatic complaints may be a prominent feature of a depressive illness.

Six out of the 27 patients who could be adequately examined were thought to be significantly depressed, which means that roughly a fifth of the general run of these patients seen in an out-patient clinic may be suffering from depressive illness. It may well be that the true proportion is very much greater as this includes only those patients who were overtly suffering from depression. Certainly Kreitman et al. (1965) found depression common among their hypochondriacal patients. It remains possible that in some of these patients the process of somatization with its frequent accompaniment of denial of depression may have more completely hidden the underlying depressive process. In practice, when a patient says that he is in pain and also depressed because of the pain it is very easy to slip into his fallacious view of the sequence rather than to see him as a depressed person one of whose symptoms is a somatic complaint. There is no need to elaborate on the importance of this distinction from the point of view of treatment. Patient 2 (see appendix) illustrates these difficulties.

Engel (1959) conceptualizes psychogenic pain as a means of alleviating guilty, depressive feelings by a form of expiation in suffering. In the absence of this form of relief he sees the individual as more likely to be overwhelmed by unbearable mental pain. To the extent that the mechanism is more or less 'successful,' so the individual may show just pain, depression, or a mixture of both.

Three case histories illustrating some of the aetiological factors of non-organic abdominal pain are appended.

PATIENT 1 A man, aged 34, had suffered from abdominal pain for nine years. The pain was experienced in the epigastrium and was often associated with eructation.
The onset of the pain seemed to coincide with his setting up in partnership with his very dominant brother and the very hard work that he had been involved in since then.

His father is alive. He has a bad temper but rarely shows it to the children. The mother died when the patient was aged 4 years. His father has never liked talking about her: there are no photographs in the house. The patient has recently gathered that she had a rather fiery temper. He was put into a residential home after her death. The father remarried two years later and the family was reunited. The stepmother was actively cruel to the children and kept them short of food, to such an extent that she was imprisoned for three months when the patient was aged 8 . After coming out of prison she seems to have sustained a change of heart and the patient states that the whole family decided to 'ignore' the past.

The patient has two full siblings and three half siblings. He has an older brother of very aggressive temperament who is a tough, ambitious businessman with whom he now works in partnership. His younger brother is a 'nervous twitchy' person who is employed by the two brothers. His schooling was marred by the many changes necessitated by his moves. He was apprenticed at the firm in which is father was a foreman, but his career was interrupted by National Service with a paratroop regiment. After discharge he went back to his former employers, later to leave with his elder brother as described.

He married at the age of 24. He is very fond of his wife but suffers from a sense of social and educational inferiority with her. About five years ago he had reason to believe that she was unfaithful to him and since then has felt very suspicious of her to an extent that he himself believes may be morbid. She is less desirous of sexual relations than he is and he finds this frustrating. They have two sons, the older of which is attending a child guidance centre because of his disturbed behaviour. There is no past medical history of any note. He was admitted to a mental hospital for a week-end in 1962 because he appeared to be so anxious and depressed. At the time he attributed his condition to difficulties with the older brother. The condition cleared rapidly.

$\mathrm{He}$ is a great perfectionist in his work (tile laying), to such an extent that he is slower than he should be. He hates having arguments and has always tended to weep easily when upset. He is a moderate smoker and drinker.

The features of note about this patient are the history of brutality in childhood perpetuated later by the bullying of the older brother. It is of interest to speculate that the different character formations of these three brothers, each exposed to the same traumata of maternal death and repressive stepmother, are somehow related to the different ages at which they suffered these events. The patient was very aware of his resentment against his brother and his wife but was unable to express either. His pain was greatly relieved by the administration of tranquillizers.

PATIENT 2 A man, aged 34, has been troubled by severe 
epigastric pain for 10 years. The pain began after he had assisted his brother-in-law in an undertaking job that involved his viewing a corpse for the first time in his life, and for the subsequent month he was unable to get the image of the corpse out of his mind. He became increasingly nauseated and the epigastric pain which started with the bouts of nausea has remained with him ever since. His appendix was removed in 1955 without relief. Simultaneously with the onset of the pain he developed psoriasis which has persisted. His father died in 1963. The patient had been very attached to him and was depressed for some months after this. His mother is a rather nervous person with psoriasis and chronic indigestion, who has at times threatened suicide.

The patient is the second of five children. One sister has received ECT for a possibly depressive illness. One brother seems to be a very feckless person who has caused great concern to the family The patient often helps him with money.

The patient's childhood was unexceptional. $\mathrm{He}$ performed his military service and on leaving the army worked with his brother-in-law largely as a jobbing decorator, leaving him after the episode with the corpse. Since then he has driven heavy lorries, at first as an employee but since 1961 for himself. In that year he bought a motorized concrete mixer which involved him in heavy debt, made worse by poor financial advice that led to his having far more in the way of expenses than he should have had. Things were straightened out in 1964 only for him to find that the demand for this type of service was slackening and he was advised to get another sort of lorry for carrying sand ballast, which would involve him in further outlay. It was at this juncture that he was seen.

His marriage is a happy one. $\mathrm{He}$ is very fond of his wife and very dependent on her; e.g., she accompanied him on all his hospital visits even when he was recovered.

Intercourse was satisfactory even though they practised coitus interruptus. Their eldest son gave them considerable worry by suffering from recurrent limb pains until the age of 8 . The patient was bitterly disappointed when the second child turned out to be another boy, and, although reconciled, it is of interest that the child was born at the onset of the patient's troubles.

In personality the patient was very much a perfectionist. He tended to ruminate on his problems and extended help to his brother even at a time when he was short of money himself. He was mildly phobic when his work led him to mount scaffolding or to go onto a flat roof that was more than two or three storeys.

Initially he was treated with Perphenazine with apparently good results. He decided to go back to work and to buy a new lorry. Unfortunately, the licence that he required for this work was unexpectedly opposed and he went through a period of great anxiety during which he became increasingly depressed. Nonetheless he obtained the licence and began to work, but instead of relief, his depression deepened until the wife telephoned asking for him to be seen urgently.

He was depressed, self reproachful with suicidal ideas. He was tearful and felt distressed at the least contact with anyone outside his intimate circle. Despite this deteriora- tion the pain had improved and coincident with the worsening of the depression the pain had stopped bothering him. He was urged to come into hospital but refused saying that he would court financial disaster if he did not continue to work whatever his condition. Amitryptilline, $150 \mathrm{mg}$. daily, was tried, and at the end of the first week he began to improve. He felt very well after a month, free from depression and pain. He has remained well for the five months since then.

This patient illustrates very well the relationship between the suffering of physical pain and depression (mental pain). Using Engel's concepts, his pain to some extent was a physical expression of his depression for which there was no need when the depression itself became overt. The circumstances of its onset were interesting and it would be illuminating to know how much the understandable morbidity at viewing a corpse was complicated by his rejection of the son born about this time. 'Choice' of symptom was probably to some extent dictated by his mother's proneness to indigestion. The psoriasis that he shared with his mother is another point of interest.

PATIENT 3 A man, aged 30, had suffered epigastric pain for five to six years. It was at times associated with nausea. It had begun when he was first betrothed. His marriage was still unplanned, he said, because he had wanted to save some money and also would like to get his pain cleared up first. His father had died in 1964 of carcinoma of the stomach. He had been a life-long sufferer from abdominal pain for which an organic cause had never been found. Three of father's sisters, a brother, and his mother had suffered similarly. All were very careful about their food and about most other things as well, such as being in a draught or crossing the road. The mother remains well and he continues to live with her. He has one sister who tends to be rather moody.

He was a somewhat nervous child and did not take his $11+$ because of his anxieties. Since leaving school he has worked as a skilled motor mechanic.

He claims to be very happy with his fiancée and has a full sexual life. There is no previous medical or psychiatric history of any note. He tends to be a perfectionist in his work and finds it very difficult to be unoccupied. He likes driving recklessly and his friends tell him that he takes undue risks. He looks rather younger than his years and feels that this counts against him at work.

He had a period in hospital with a milk drip which gave him some relief. Following discharge from hospital his symptoms returned but he was further helped by a tranquillizer, remaining pain free for the six months he was under review.

The major point of interest is the very strong family history of nervous indigestion on his father's side, psychologically complicated by his father's dying of carcinoma of the stomach that must make 
it very difficult for him to accept completely medical assurance about the innocence of his own complaint. This situation has arisen repeatedly among our patients.

\section{SUMMARY}

A consecutive series of patients presenting to one physician in a medical out-patient department over the course of a year complaining of abdominal pain for which no organic cause could be found were assessed physically and psychologically.

Most of the patients complained of epigastric pain associated with distension, belching, nausea without vomiting, or loss of weight. These symptoms, together with a lack of periodicity in the pain and failure to gain relief from food, were found to differ significantly from a carefully controlled group of patients with peptic ulcers.

On the psychosocial side, the number of parents of the entire group of patients who had themselves suffered from abdominal pain were significantly in excess of a control group with organic pain, and furthermore many of them died suffering in this manner. The patients came from significantly larger sibships than a control population and scored high for 'neuroticism' as estimated by a personality inventory. The patients' symptoms often began in a setting of bereavement, in some cases with recurrences on similar occasions, or otherwise followed by some clear upheaval in their lives.

A number of patients were considerably depressed when seen and treatment for depression was followed by disappearance of the pain. Some appeared to benefit from the cathartic nature of their psychiatric interview. In a further group of patients their symptoms either disappeared or were greatly improved by Perphenazine or sodium amytal but not by a placebo.

The significance of these findings and the possible mechanisms that induce pain, and particularly abdominal pain, in these patients is discussed.

We would like to thank Dr. G. D. Hadley and Dr. P. A. J. Ball for allowing us to investigate patients attending their out-patient clinics. We would like to thank them and Dr. H. H. Wolff for their helpful advice and criticism in the preparation of this paper.

\section{REFERENCES}

Apley, J. (1959). The Child with Abdominal Pains. Blackwell, Oxford.
Barfred, A. (1959). Pseudo-ulcer and true peptic ulcer. In Proc. Wld. Congr. Gastroenter., 1958, vol. 1, pp. 352-359. William and Wilkins, Baltimore.

Beck, I. T., Kahn, D. S., Lacerte, M., Solymar, J., Callegarini, U., Geokas, M. C., and Phelps, E. (1965). 'Chronic duodenitis' a clinical pathological entity? Gut, 6, 376-383.

Blendis, L. M., Cameron, A. J., and Hadley, G. D. (1967). Analysis of 400 examinations using the gastrocamera, Gut, 8, 83-87.

Brummer, P., and Hakkinen, I. (1959). X-ray negative dyspepsia. A follow-up study. Acta med. scand., 165, 329-332.

Chaudhary, N. A., and Truelove, S. C. (1962). The irritable colon syndrome. Quart. J. Med., 31, 307-322.

Dahlqvist, A. (1964). Method for assay of intestinal disaccharidases. Analyt. Biochem., 7, 18-25.

Engel, G. L. (1951). Primary atypical facial neuralgia. An hysterical conversion symptom. Phsychosom. Med., 13, 375-396.

- (1959). 'Psychogenic' pain and the pain prone patient. Amer. J. Med., 26, 899-918.

Eysenck, H. J., and Eysenck, Sybil, B. G. (1964). Manual of the Eysenck Personality Inventory. University of London Press.

Gonda, T. A. (1962). The relation between complaints of persistent pain and family size. J. Neurol. Neurosurg. Psychiat., 25, $277-281$.

Hadley, G. D. (1965). The gastro-camera. Brit. med. J., 2, 1209-1212.

Haemmerli, U. P., Kistler, A. J., Ammann, R., Marthaler, T., Semenza, G., Auricchio, S., and Prader, A. (1965). Acquired milk intolerance in the adult caused by lactose malabsorption due to a selective deficiency of intestinal lactase activity. Amer. J. Med., 38, 7-30.

Hill, O. W. (1967). Psychogenic vomiting and hypokalaemia. Gut, 8, 98-141.

Jones, F. A., and Gummer, J. W. P. (1960). Clinical Gastroenterology, p. 332. Blackwell, Oxford.

Kreitman, N., Sainsbury, P., Pearce, K., and Costain, W. R. (1965). Hypochondriasis and depression in out-patients at a general hospital. Brit. J. Psychiat., 111, 607-615.

Krupp, G. R. (1965). Identification as a defence against anxiety in coping with loss. Int. J. Psycho-Anal., 46, 303-314.

Kurokawa, T. (1959). Clinical observations on peptic ulcer in Japan. Proc. Wld. Congr. Gastroenter., 1958, vol. 1, p. 378. Williams and Wilkins, Baltimore.

Maclay, I. (1965). The 'functional' medical out-patient. Brit. J. Psychiat., 111, 34-38.

McMichael, H. B., Webb, J., and Dawson, A. M. (1965). Lactase deficiency in adults. A cause of 'functional' diarrhoea. Lancet, $1,717-720$.

Maddock, W. G. (1952). Importance of air in gastrointestinal distension. Surg. Clin. N. Amer., 32, 71-80.

Merskey, H. (1965). Psychiatric patients with persistent pain. $J$. Psychosom. Res., 9, 299-309.

Ostrow, J. D., and Resnick, R. H. (1959). Hyperchlorhydria, duodenitis and duodenal ulcer: a clinical study of their interrelationships. Ann. intern. Med., 51, 1303-1328.

Roth, J. L. A., and Bockus, H. L. (1957). Aerophagia: its aetiology, syndromes and management. Med. Clin. N. Amer., 41, 16731696.

Trethowan, W. H., and Conlon, M. F. (1965). The Couvade syndrome. Brit. J. Psychiat., 111, 57-66.

Truelove, S. C., and Reynell, P. C. (1963) Diseases of the Digestive System, p. 155. Blackwell Scientific Publications, Oxford.

Welsh, J. D., Rohrer, G. V., and Walker, A. (1966). Human intestinal disaccharidase activity. 1. Normal individuals. Arch. intern. Med. (Chic.), 117, 488-494.

Whitby, J. (1958). Dyspepsia with negative X-ray findings (B.M.A. Annual Meeting. Section of Gastro-enterology). Brit. med. J., $2,313$.

White, B. V., Cobb, S., and Jones, C. M. (1939). Mucous Colitis: a Psychological Medical Study of 60 Cases. Psychosomatic Medicine Monogr. no. 1. National Research Council, Washington.

Wolfe, S. (1965). The Stomach. Oxford University Press, New York. 